\title{
Clarifying the Relationship of Design Thinking to the Military Decision-Making Process
}

\author{
By \\ Thomas S. Fisher, University of South Florida
}

$\mathrm{T}$ he complexity of today's operational environment where military organizations are conducting campaigns to address some of the nation's most urgent problems has grown exponentially (Mensch \& ${ }^{2}$ Rahschulte, 2008). In order to address this expanding complexity, the Defense Department introduced 'design' into its problem-solving doctrine as a method to understand the new and dynamic challenges associated with this increasingly complex environment and provide a tool to augment its current military decision-making process. However, it appears military 'design' as prescribed by the Department today may be only marginally

To address expanding complexity, the U.S. Defense Department introduced 'design' into its problem-solving doctrine. This study seeks to understand the challenges with current design thinking as well as Design Science Research and its utility in solving complex problems. effective at producing viable solutions for solving the complex, ill-structured problems that current military campaigns were developed to resolve.

This apparent inability to produce viable solutions to the complex problems facing the United States over the last two decades may be due to a lack of understanding among the joint force regarding design thinking and its application to problem-solving. The 19 years that coalition forces have spent in Afghanistan may be indicative of the challenges planners have in addressing complexity within today's operating environment. The nine years initially spent in Iraq followed by the current six years in Iraq and Syria may be another. Any number of operations including those in the Balkans, Viet Nam, and Korea point to an ability of the Department to successfully execute tactical battles and operations at discreet locations over time but a corresponding inability to deliver 'strategic wins' (Summers, 1995). If military Design is intended to enable operational success leading to the 'strategic win' desired by our national leadership, then why isn't it succeeding instead of delivering what some would characterize as a Pyrrhic victory? (Mossman, 2002)

Keywords: Complexity, Problem solving, Planning, Strategy, Reasoning, Sense-making

Copyright $\odot 2021$ Thomas S. Fisher. This article is published under a Creative Commons BY-NC license. Permission is granted to copy and distribute this article for non-commercial purposes, in both printed and electronic formats 
Design thinking is a relatively new scientific construct that supports problem-solving but there is no consistent definition either in Academia or within military doctrine. For the purpose of this study, Design thinking was defined as an intellectual approach to problem-solving consisting of two distinct elements: Design Theory and Design Science. Design Theory is the logical foundation that underpins the reasoning required to develop an artificial solution and adapt it to practical application (Simon, 1969). Design Science provides the systematic framework for developing the artifact itself, implement the solution and evaluate the impact of solution on resolving, or at a minimum reshaping, the problem.

Much of the changes to the problem-solving process and the introduction of design thinking into military doctrine is due to the increasing complexity of the operational environment. As noted in the study, there are varying methods within the DOD for using design thinking to better efforts focused on solving problems. However, the reason for doctrinal publications within the Department is to ensure all the services speak a common language. As the review of current design processes show, different approaches result in differing definitions that complicate the joint force's ability to solve problems from a common perspective. Therefore, to address the issue, this research examined the following research questions:

- What are the common challenges among the lived experiences of senior Plans Chiefs when recommending solutions for solving complex problems?

- What process (artifact) best enables design approaches to support problem-solving for the Plans Chief?

This study is comprised of exploratory, qualitative research that examined these questions using a combination of interviews, case research and design science research regarding the relationship of design thinking to the military problem-solving process. The research began with interviews of Plans Chiefs from the Department's most experienced warfighting headquarters from the last two decades to identify insights and data regarding the efficacy of current military design thinking in the Department's problem-solving process and develop an improved design model. Additionally, case research involving observations of planning teams conducting problem-solving processes in situ to develop solutions to crises provided corroborating data for the interviews. The case research identified current practitioner design challenges and required products to validate subject matter expert (i.e., the Plans Chiefs) observations and recommendations for improving military design.

\section{Findings}

To determine the utility of Design thinking in solving complex problems one must identify the challenges induced by greater complexity within the operational environment upon the problem-solving

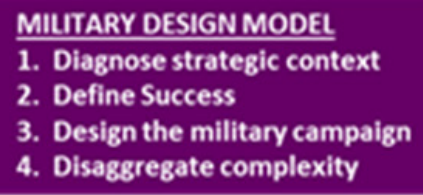

MILITARY DESIGN MODEL

2. Define Success

3. Design the military campaign 4. Disaggregate complexity

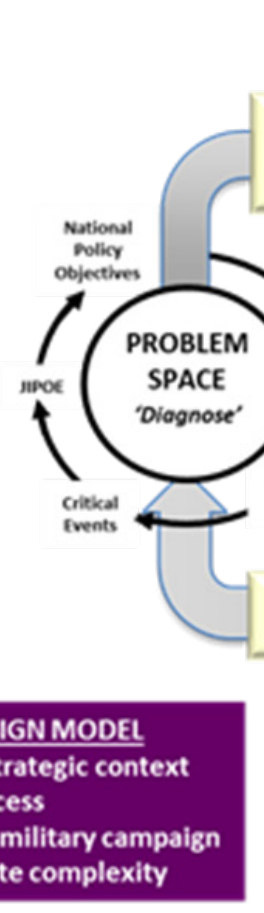

Figure 1. The proposed Recursive, Dynamic Military Design Model (MDM)

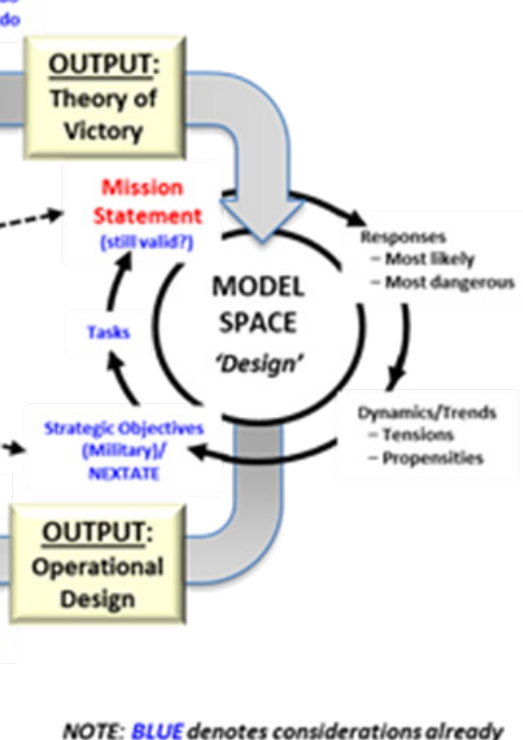

port of the DOD problem-solving process 
process. Interviews with the Plans Chiefs provided the data needed to accurately diagnose the challenges and shortcomings in the current process. Comparing the shortcomings of the process prior to the introduction of design into military problem-solving with the shortcomings that remain or are a result of the introduction of design thinking provided the impetus for designing a new model (i.e. artifact).

From both the academic literature and Defense doctrine two components were identified as critical parts of the design process: The problem space and operational space. The problem space is the component that diagnoses the problem to be solved within the operational environment and the operational space is the environment within which the artifact will affect the physical environment to solve the problem defined in the problem space. The operational space is where the current military design process creates its operational approach for solving the problem though the development of a campaign using the current MDMP process (DOD, 2017).

However, the data collected suggest deriving the problem by comparing the current operational environment to a desired operational environment is problematic. As there is normally great uncertainty as to the endstate desired by senior policy makers along with substantial difficulty in defining and then gaining concurrence of the efforts to achieve that endstate among the policy makers is a flawed approach. Instead, military design must account for a distinct examination of a solution space to determine a theory that translates military action into a strategically successful outcome by developing a hypothesis that the artifact will test. Because this definition of success was not, in most cases, defined prior to the initiation of military operations the U.S. continues to spend significant resources in places such as Iraq and Afghanistan. This problem is compounded by changes in Administrations over time (e.g. Bush Administration to Obama Administration to Trump Administration). Therefore, to rectify this issue the MDM adds this space for examining the solution and developing its associated Theory of Victory.

A fourth space is also added in the MDM called the model space. Once there is an agreed upon definition of success with an associated theory of victory, one must build a model of the campaign that provides the operational logic of the campaign. This model shows how the crisis/problem will play out over time and the scope of the military involvement in resolving that problem over time. In science, models are created in a conceptual space to better allow us to predict the future. The depiction of the proposed MDM is provided in Figure 1.

\section{Conclusions}

The contributions from this research can be consolidated into three distinct areas: 1 ) a contribution to enhancing our understanding of the reasoning underlying scientific method, 2) the development of a model for designing military campaigns that can be generalized to broader design theory, research and practice, and 3) recommended modifications for plans organizations within the DOD.

First, the research suggests abduction is a better reasoning system for designing an artifact because at the heart of design is the evaluation of an artifact in practice with subsequent modifications to the rationale that led to the development of the current artifact (i.e. the solution). Because this form of reasoning uses inferences based on identified facts and assumptions to define success, the evolution of an artifact is directly tied to the logical evolution of design that comes from the artifact in practice and re-assessing our collective understanding of the known knowns (facts), known unknowns (assumptions) and the unknown unknowns (inferences). Based on the analysis of the data and resulting model for military design, a modification to the scientific method model of the cycle of research is recommended.

Second, this study created a more useful model for executing military design that leads to the current linear planning process. Data supporting its greater utility was derived from both observations of military design in practice as well as an evaluation by subject matter experts. There are a couple of key reasons for this increased utility. In addition to the Problem Space and the Operational Space, the study identified two additional design spaces required for more effective military design.

The model proposed a novel concept of developing a Theory of Victory within the Solution Space that includes a hypothesis explaining why the use of military resource will achieve the desired outcomes and why those outcomes will solve the problem defined in the Problem Space. It also introduced the concept of operational design as a model of the proposed artifact's interaction with the operational environment and its predicted degree of relative success and potential second and third order effects.

Through observations of current design efforts, the case research also discovered 'living' products from practice (e.g. Strategic Context, Problem Statement, Theory of Victory) that support the deliberate and crisis planning processes. These products derived and developed from real-world design efforts corroborated some of the observations of the subject matter experts and provided useful examples of 'best practices' for the Dynamic-Recursive Military Design Model (MDM).

A final contribution of the MDM was the requirement to broaden the orientation of current military assessment doctrine for military campaigns to assessing the impact of the Campaign on the Problem Space. Current assessments focus on whether an or- 
ganization is executing the campaign in a manner that is creating the intended effects on the operational environment and if the actions of the organization to produce those effects are being performed in the prescribed standard. This tells an organization if they are conducting the directed operations of the campaign in an effective manner and if they performed their duties while executing those operations well. What is not assessed is whether the campaign is solving the problem. In other words, the organization may be executing the campaign in an outstanding fashion resulting in a positive assessment even though the campaign itself is not solving the problem for which it was created. So, organizations continue to execute the campaign as planned but expect a different result; what some have defined as 'insanity'.

Overall, the conclusions of the study based on the data collected provides clarity toward linking academic theories and 'best practices' with establish problem-solving procedures - many of which are applicable to problem-solving and decision-making outside the defense department. As the research was exploratory, the study also identified areas for future research in order to further refine the MDM.

\section{References}

Department of Defense. (2017). Joint Planning (JP 5-0).

\section{Authors}

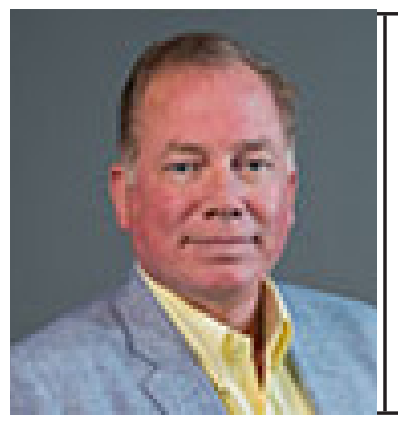

Thomas S. Fisher, as a retired colonel from the U.S. Army currently working at the MacDill Air Force Base in Tampa, served 30 years in the United States, Europe and the Middle East. He currently serves as an advisor within the U.S. Department of Defense, developing plans and orders for military personnel conducting operations in the Middle East. He received a master's degree in strategic studies in 2011 from the Army War College in Carlisle, Pennsylvania; a master's degree in national security in 2002 from the Navy War College in Newport, Rhode Island; and a master's degree in journalism in 1995 from Marshall University in Huntington, West Virginia. He earned a bachelor's degree in speech/ communication in 1987 from the University of Minnesota in Minneapolis. 